\title{
No progress on diversity in 40 years
}

\author{
Ethnic and racial diversity are extremely low among United States citizens and permanent residents who earned \\ doctorates in earth, atmospheric and ocean sciences. Worse, there has been little to no improvement over the past \\ four decades.
}

\section{Rachel E. Bernard and Emily H. G. Cooperdock}

T he geosciences tackle the complexities of the Earth. Geoscientists also study how we, as a society, affect - and are affected by - the planet we live on. Complex problems that influence all segments of society, such as demands on diminishing natural resources and climate change, require the ingenuity of investigators with a broad variety of backgrounds. Increased diversity has clear benefits for scientific advancement: different perspectives and life experiences spark unique questions and approaches to problem solving ${ }^{1}$. Collaborations involving a diverse group of people are more creative at tackling problems and lead to higher levels of scientific innovation ${ }^{2}$. Nevertheless, the geosciences are the least diverse of all STEM (science, technology, engineering and mathematics) fields.

We noticed the lack of ethnic and racial diversity among our peers as soon as we entered our $\mathrm{PhD}$ programme. The uniformity worsens from undergraduate to graduate to faculty level. The data support this perception; years of outreach have yet to make any significant strides toward increasing diversity at the $\mathrm{PhD}$ level. Efforts to increase diversity have primarily been focused on feeding the pipeline in schools and at the undergraduate level. Yet, at all degree levels, the geosciences remain the least diverse discipline within STEM ${ }^{3}$.

If we want to broaden the ethnic and racial range of people in the geoscience faculty, we first need $\mathrm{PhD}$ graduates who can fill the positions. We highlight the persistence of the geoscience doctorate diversity problem in the United States (US), on the basis of more than 40 years of publicly available demographic data for doctorates in the earth, ocean and atmospheric sciences earned by US citizens or permanent residents (Box 1$)^{4}$. Whereas significant gains have been made in terms of gender balance among $\mathrm{PhD}$ recipients in the geosciences, there are few signs of improvement on the ethnic and racial diversity front at the doctorate level. In light of this failure to broaden the base of PhD-level researchers, the community needs to rethink current strategies aimed at diversifying our academic departments.

\section{Race and ethnicity over time}

The number of $\mathrm{PhDs}$ awarded in the earth sciences to US citizens and permanent residents has been relatively stable - around 350 per year since 1973 (Fig. 1a) - whereas the number of ocean and atmospheric science PhDs have risen remarkably in the latest decade. Taking all three disciplines together, about $60 \%$ more $\mathrm{PhDs}$ were awarded in 2016, compared to 1973.

When we combine all three subdisciplines - ocean, atmosphere and earth sciences (Box 1) - and stratify by self-reported ethnicity, it becomes clear that the vast majority of $\mathrm{PhDs}$ ( $86 \%$ over all years and $85 \%$ in 2016 alone) were awarded to students who identify as non-Hispanic White people (Fig. 1b; Table 1). Even more depressingly, over the 40 years covered by our data, the representation of students from underrepresented minorities (American Indian or Alaska Native, Black or African American, and Hispanic or Latino groups $)^{4}$
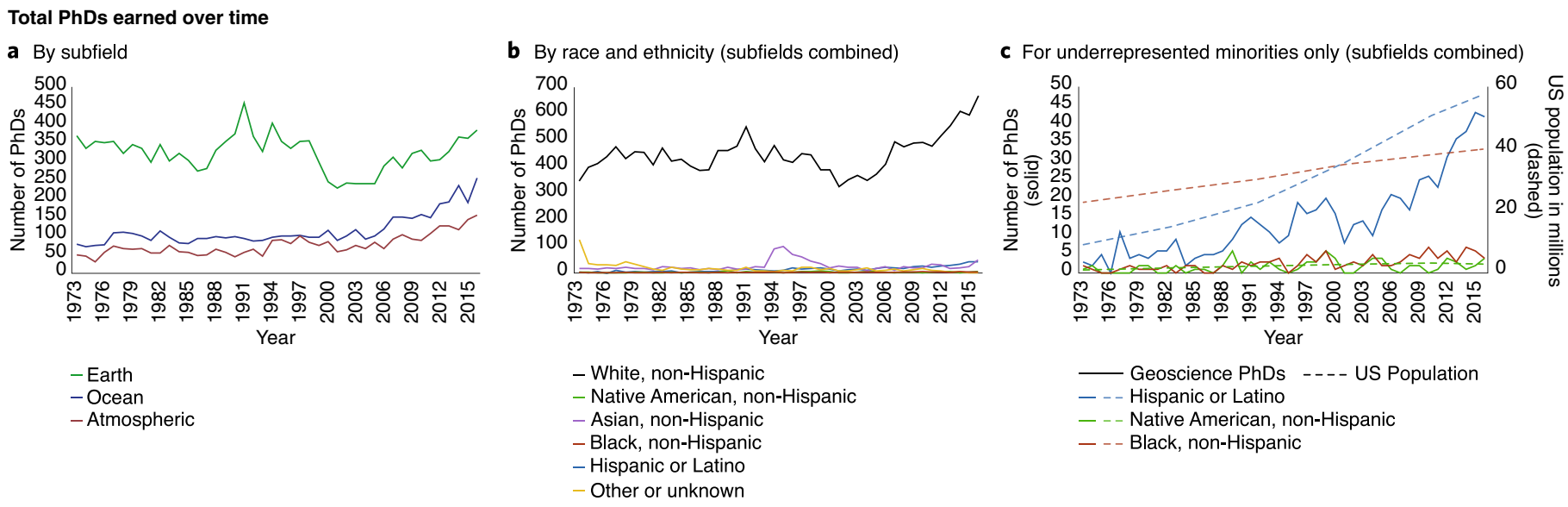

Fig. 1 | PhDs earned by US citizens and permanent residents between 1973 and 2016. a, The total number of PhDs for all races, ethnicities and genders combined have fluctuated around 350 for the earth sciences, but have taken an upward turn from a stable base level in the last decade or so for ocean and atmospheric sciences. $\mathbf{b}$, The largest race/ethnicity category by far is the White non-Hispanic PhD group. c, Focusing on what the NSF considers to be underrepresented minorities (that is, excluding White non-Hispanics and Asian non-Hispanics), and comparing with the increasing share of these groups in the US population (measured by decadal census and 2016 estimate), it becomes clear that gains in Hispanic or Latino PhDs largely reflect an increase in the relevant population in the US, and that there are no gains in PhDs earned among the other underrepresented groups. Data in a-c run from 1973 to 2016. 


\section{Box 1 | The data}

The basis for our assessment is the Survey of Earned Doctorates (SED), an annual census, sponsored by several federal agencies, of individuals who receive research doctoral degrees from accredited US academic institutions ${ }^{4}$. The findings are reported through the NSF's National Center for Science and Engineering Statistics. The data come from survey forms distributed by graduate coordinators at doctorate-awarding institutions or direct e-mails to recent graduates. Response rates in recent years have been about $90 \%$. For our purposes, we chose to look at the SED demographic data for US citizens and permanent residents since 1973, the year SED began collecting race and ethnicity data.

SED data were mined from multiple sources in order to have as complete a record as possible (see Supplementary Information).

Subfield categories. We collected data from the following specific subfields of the SED dataset: (1) Atmospheric Science and Meteorology; (2) Geological and Earth Sciences; and (3) Ocean/Marine Sciences (all fall within the broader category of 'Physical Sciences'). For clarity and simplicity, we refer to the three subfields as 'atmospheric', 'earth', and 'ocean' sciences, and refer to the three collectively as 'the geosciences'.

Doctorate recipients filling out the SED are provided with a list of several academic subjects and are prompted to self-select which subject best describes

has essentially been stagnant when compared with the proportion of the relevant groups in the US population (Fig. 1c).

The very low number of 'other race or unknown' students (Fig. 1b) suggests their area of research (for example, Chemical and Physical Oceanography is a subject within the Ocean/Marine Sciences subfield). For a complete list of subjects provided in the SED survey form for the three subfields, see Supplementary Information.

Racial and ethnicity categories. The SED divides US citizens and permanent residents into (a) Hispanic or Latino; and the following 'Not Hispanic or Latino' racial categories: (b) American Indian or Alaska Native; (c) Asian; (d) Black or African American; (e) White; (f) more than one race; and $(\mathrm{g})$ other or race unknown. Doctorate recipients who report Hispanic or Latino ethnicity, regardless of racial designation, are counted as Hispanic or Latino. Therefore, there may be people who consider themselves White, for example, who are counted only in the Hispanic or Latino category. For changes in these categories over time, see Supplementary Information.

We refer to underrepresented minorities as groups that are underrepresented in science and engineering, relative to their numbers in the US population (as defined by NSF $)^{4}$. These groups include American Indian or Alaska Native (referred to as 'Native American'), Black or African American (referred to as 'Black'), and Hispanic or Latino groups.

Gender categories. SED gender categories are self-reported, and limited to male and female.

that the race and ethnicity questions were rarely skipped; the spike in Asian $\mathrm{PhD}$ recipients in the mid-to-late 1990s also appears in other fields, such as chemistry and economics, and is thus probably the result of a change in the categorization.

We are alarmed that the proportion of underrepresented minorities among $\mathrm{PhD}$ recipients in the geosciences has not improved in any meaningful metric over more than four decades, despite the efforts by our community to try to increase diversity, particularly in the past 20 years following the development of the National Science Foundation (NSF)'s Broader Impacts initiative ${ }^{5}$.

\section{Gender over time}

Predictably, in 1973, men vastly outnumbered women (Fig. 2, Table 1). However, the percentage of women earning PhDs has steadily climbed in all subfields; and in the ocean sciences, the number of women has even surpassed the number of men earning PhDs since 2009 (Fig. 2c). Women briefly outnumbered men in the earth sciences for one year (Fig. 2a).

In the earth sciences, where the total number of $\mathrm{PhDs}$ awarded has remained relatively constant over the past 40 years (Fig. 1a), the absolute number of doctorates going to men has actually decreased substantially over time from 347 male recipients of PhDs in 1973, to 212 in 2016. This trend holds only for White male students; for men of other ethnicities or races, no similar trend is observed. This is not at all unique to the earth sciences. For example, data from the Survey of Earned Doctorates $^{4}$ (SED) show that over the same period, the number of doctorates going to White men in economics, psychology and physics has decreased by $50 \%$.

\section{The bigger picture}

In 2016 , only $6 \%$ of geoscience doctorates awarded to US citizens and permanent residents went to students from underrepresented minorities, a group who made up $31 \%$ of the US population that year ${ }^{6}$ (Table 1 ). With this number, the geosciences have the lowest proportion of

\section{Per cent of PhDs earned by gender over time}

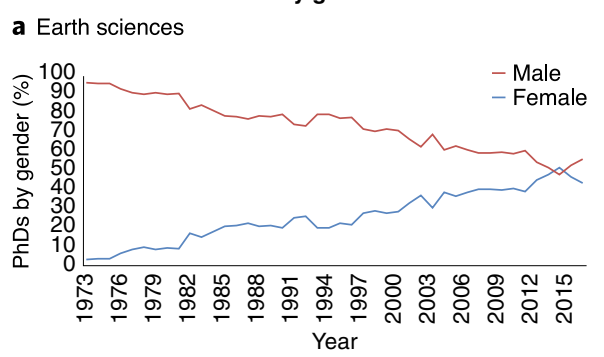

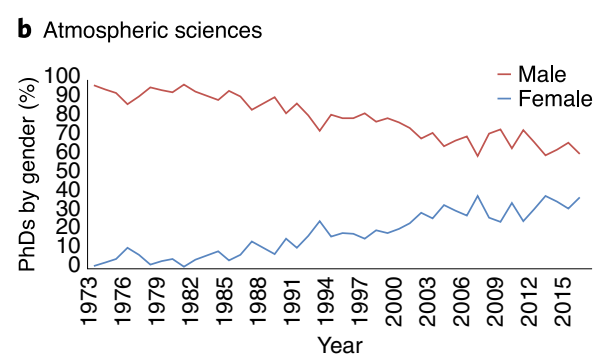

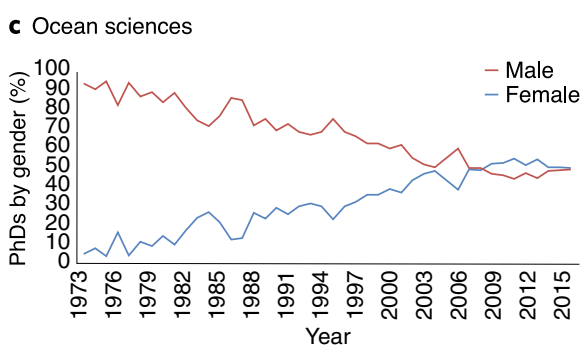

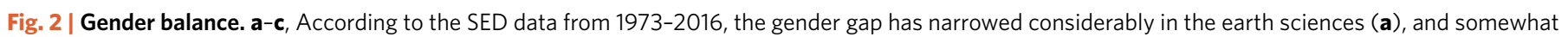
less in the atmospheric sciences (b). In the ocean sciences, more women than men have earned PhDs since 2009 (c). Refer to Box 1 for information on subfield categories. Data in a-c run from 1973 to 2016. 
Table 1 | Total number of doctorates awarded from 1973 to 2016, along with calculated percentages of race, ethnicity and gender for the most recent year in the dataset

\begin{tabular}{|c|c|c|c|c|c|c|c|c|c|c|}
\hline \multirow[b]{2}{*}{$R \& E$} & \multicolumn{2}{|c|}{ Earth } & \multicolumn{2}{|c|}{ Ocean } & \multicolumn{2}{|c|}{ Atmospheric } & \multicolumn{2}{|c|}{ All geosciences } & \multicolumn{2}{|c|}{$\begin{array}{l}2016 \text { comparative } \\
\text { percentages }\end{array}$} \\
\hline & $\begin{array}{l}\text { Cumulative } \\
\text { number }\end{array}$ & $\begin{array}{l}\text { Per cent } \\
\text { in } 2016\end{array}$ & $\begin{array}{l}\text { Cumulative } \\
\text { number }\end{array}$ & $\begin{array}{l}\text { Per cent } \\
\text { in } 2016\end{array}$ & $\begin{array}{l}\text { Cumulative } \\
\text { number }\end{array}$ & $\begin{array}{l}\text { Per cent } \\
\text { in } 2016\end{array}$ & $\begin{array}{l}\text { Cumulative } \\
\text { number }\end{array}$ & $\begin{array}{l}\text { Per cent } \\
\text { in } 2016\end{array}$ & $\begin{array}{l}\text { All S\&E } \\
\mathrm{PhDs}^{\mathrm{c}}\end{array}$ & US population ${ }^{\mathrm{d}}$ \\
\hline White & 12,279 & 86 & 4,435 & 87 & 2,856 & 75 & 19,570 & 85 & 73 & 61 \\
\hline Asian & 622 & 5 & 237 & 6 & 324 & 11 & 1,183 & 6 & 10 & 6 \\
\hline Hispanic or Latino & 335 & 4 & 198 & 4 & 95 & 9 & 628 & 5 & 7 & 18 \\
\hline Black & 115 & 1 & 58 & 0 & 59 & 4 & 232 & 1 & 6 & 12 \\
\hline Native American & 52 & 1 & 15 & 0 & 7 & 1 & 74 & 1 & $<1$ & 1 \\
\hline Other or unknown & 523 & $<1$ & 145 & $<1$ & 95 & 0 & 763 & $<1$ & 1 & $<1$ \\
\hline Two or more races ${ }^{\mathrm{a}}$ & 92 & 3 & 50 & 3 & 22 & 1 & 164 & 3 & 3 & 2 \\
\hline Total & 14,018 & 100 & 5,138 & 100 & 3,458 & 100 & 22,614 & 100 & 100 & 100 \\
\hline Per cent URM ${ }^{b}$ & & 6 & & 4 & & 13 & & 6 & 13 & 31 \\
\hline Gender & $\begin{array}{l}\text { Per cent over } \\
\text { all years }\end{array}$ & $\begin{array}{l}\text { Per cent } \\
\text { in } 2016\end{array}$ & $\begin{array}{l}\text { Per cent over } \\
\text { all years }\end{array}$ & $\begin{array}{l}\text { Per cent } \\
\text { in } 2016\end{array}$ & $\begin{array}{l}\text { Per cent over } \\
\text { all years }\end{array}$ & $\begin{array}{l}\text { Per cent } \\
\text { in } 2016\end{array}$ & $\begin{array}{l}\text { Per cent over } \\
\text { all years }\end{array}$ & $\begin{array}{l}\text { Per cent } \\
\text { in } 2016\end{array}$ & $\begin{array}{l}\text { All S\&E } \\
\text { PhDs }^{c}\end{array}$ & US population ${ }^{d}$ \\
\hline $\begin{array}{l}\text { Per cent male (all } \\
\text { R\&Es) }\end{array}$ & 74 & 56 & 65 & 50 & 78 & 62 & 73 & 55 & 53 & 49 \\
\hline $\begin{array}{l}\text { Per cent female (all } \\
\text { R\&Es) }\end{array}$ & 26 & 44 & 35 & 50 & 22 & 38 & 27 & 45 & 47 & 51 \\
\hline
\end{tabular}

anly recorded since 2001. bURM totals only include Hispanic or Latino, Black and Native American individuals. 'Source: National Science Foundation, National Center for Science and Engineering Statistics ${ }^{4}$. ${ }^{d}$ Source: Kaiser Family Foundation ${ }^{6}$. R\&E, race and ethnicity; S\&E, science and engineering; URM, underrepresented minority.

doctorate recipients from underrepresented minorities among all STEM fields: in the physical sciences, the broad field which includes the geosciences, the percentage of doctorates awarded to students from underrepresented minorities amounted to $8 \%$ (regarding other broad fields, the numbers were $11 \%$ for mathematics and computer science, $11 \%$ for engineering, $14 \%$ for life sciences and $17 \%$ for psychology and social science). Averaged over all science and engineering students, $13 \%$ of doctorates went to underrepresented minorities more than twice the percentage achieved in the geosciences, and still a very long way from an adequate representation of these groups compared to their proportion of the population ${ }^{6}$ (Table 1 ).

At $6 \%$ in 2016, the percentage of Asian Americans earning doctorates in the geosciences was roughly in line with their proportion in the US population; this group is therefore not considered to be underrepresented in STEM subjects by the NSF.

The change in gender balance is a bright spot in the data, although the field as a whole, and the atmospheric sciences in particular (Fig. 2b), still has room for improvement. However, between 2006 and 2016, female geoscience faculty representation has increased from $14 \%$ to $20 \%$, so some progress is being made ${ }^{7}$.
When and how these upward trends in female representation will translate into true gender balance at the faculty level remains to be seen.

By contrast, ethnic and racial diversity within the geosciences has stagnated, even at the doctorate level. Hispanics and Latinos are the only underrepresented group that shows improved representation; however, this increase (223\% since 1990) is largely explained by the fact that this group has grown dramatically in size (157\% since 1990) within the US population (Fig. 1c) ${ }^{8}$. Clearly, we still have a long way to go if our goal is to have a geoscience doctorate community that is representative of our wider population.

Unsurprisingly, women of colour are particularly underrepresented. Between 1973 and 2016, the numbers are bleak: only 20 Native American, 69 Black and 241 Hispanic or Latino women received $\mathrm{PhDs}$ in all three geoscience subdisciplines combined. They make up a mere 330 , or $1.46 \%$, of all doctorates awarded in over 40 years.

\section{Where to from here}

Many of us have been acutely aware of the lack of ethnic and racial diversity every time we walk into our departments, or into large international conferences such as the meetings of the American Geophysical Union or the Geological Society of America.
There, we see very few people that look like us. Indeed, as recently as 2012 , scientists from underrepresented minorities made up only $3.8 \%$ of tenured or tenure track faculty in the top 100 earth science departments.

The observation that there has been little or no progress over the past 40 years implies that the efforts from the 1990s onwards to increase diversity at the grade school and undergraduate levels have not translated into diversity at the $\mathrm{PhD}$, let alone faculty, level. Certainly, these outreach efforts are worthwhile and have probably reached hundreds to thousands of students, but they are clearly nowhere near sufficient to shift our demographics. It is entirely possible that on their own, they will never translate into diversity at the doctorate level, which is necessary to ultimately diversify at the faculty level.

As a community, we need to think deeply and seriously about why the underrepresentation of some groups is so persistent, and what initiatives we can develop to make sure students from all backgrounds feel welcomed, excited, empowered and capable of succeeding at higher education in the geosciences. Initiatives aimed at grade school and undergraduate students address some of the underlying reasons why the geosciences may be less attractive to underrepresented groups, such as lack of exposure to the natural environment, field requirements and perceptions of job prospects. 
We can think of a few actions that could specifically make geoscience doctorates more appealing to these groups. Much can be done on the department or university level, such as establishing more diversity fellowships to attract and retain graduate students. We can also take lessons from the success of other physical science disciplines that use the master's degree as a pathway to $\mathrm{PhD}$, such as transition programmes that partner minority-serving institutions with research universities through collaborative research ${ }^{10}$.

We also should think about how the current model of graduate school might not serve the specific personal interests or motivations of people from underrepresented groups. For example, research in other STEM fields finds that doctoral students of colour are more likely to be motivated by altruistic values and a desire to give back to their communities than their majority peers ${ }^{11-13}$. Perhaps encouraging or even rewarding graduate students who want to devote time to community outreach and engagement - either as a course or dissertation requirement, or as a fellowship, similar to the now-retired but successful NSF GK-12 programme ${ }^{14}$ - would go a long way to make our field relevant to more people.
Additionally, key geoscience organizations should provide specific funding for minority undergraduate and graduate students to attend their conferences, and departments and universities should provide funding for their students and faculty (regardless of race) to attend national minorityserving conferences. Increased presence at conferences such as the Society for Advancement of Chicanos/Hispanics and Native Americans in Science and the National Association of Black Geoscientists would not only serve to recruit a greater diversity of students, but promote careers and opportunities in the geosciences.

As a geoscience community, we cannot afford to miss out on the extraordinary talent that exists within currently underrepresented minority groups. We will limit the science we do if we do not become more inclusive. We need to do better.

\section{Rachel E. Bernard ${ }^{1 \star}$ and}

Emily H. G. Cooperdock ${ }^{2 \star}$

${ }^{1}$ Department of Geological Sciences, University of

Texas at Austin, Jackson School of Geosciences,

Austin, TX, USA. ${ }^{2}$ Woods Hole Oceanographic Institution, Woods Hole, MA, USA.

*e-mail: rachelbernard@utexas.edu; ecooperdock@whoi.edu
Published online: 30 April 2018

https://doi.org/10.1038/s41561-018-0116-6

References

1. Medin, D. L. \& Lee, C. D. Diversity makes better science. Association for Psychological Science https://go.nature.com/2EixIJk (2012).

2. Hong, L. \& Page, S. E. Groups of diverse problem solvers can outperform groups of high-ability problem solvers. Proc. Natl Acad. Sci. USA 101, 16385-16389 (2004).

3. Women, Minorities, and Persons with Disabilities in Science and Engineering: 2017 NSF 17-310 (National Science Foundation, 2017); https://go.nature.com/2Ip2i6A

4. Survey of Earned Doctorates. Doctorate Recipients from U.S. Universities: 2016 NSF 18-304 (National Science Foundation, 2016); https://go.nature.com/2IsXHAn

5. National Science Foundation's Merit Review Criteria: Review and Revisions NSB/MR-11-22 (National Science Board, 2011); https://go.nature.com/2GQGzHs

6. Population Distribution by Race/Ethnicity - Timeframe: 2016 (Kaiser Family Foundation, 2017); https://go.nature. com/2ElMaAo

7. Wilson, C. E. Female geoscience faculty representation grew steadily between 2006-2016. American Geosciences Institute https://go.nature.com/2uQbdMo (2017).

8. The Hispanic Population: 2010 (US Consensus Bureau, 2010); https://go.nature.com/2Iqfuba

9. Nelson, D. J. in Diversity in the Scientific Community Volume 1: Quantifying Diversity and Formulating Success (eds Nelson, D. J. \& Cheng, H. N.) 15-86 (ACS, Washington, DC, 2017).

10. Stassun, K. G. et al. Am. J. Phys. 79, 374 (2011)

11. Thoman, D. B. et al. BioScience 65, 183-188 (2015).

12. McGee, E. O. et al. J. Multicult. Educ. 10, 167-193 (2016).

13. Gibbs, K. D. Jr \& Griffin, K. A. Life Sci. Educ. 12, 711-723 (2013)

14. Mervis, J. Science 331, 1127-1127 (2011).

Additional information

Supplementary information is available for this paper at

https://doi.org/10.1038/s41561-018-0116-6. 